\title{
SLOPE INSTABILITY MONITORING BY SPACE-BORNE SAR INTERFEROMETRY: PRELIMINARY RESULTS FROM PANACHAICO MOUNTAIN (WESTERN GREECE)
}

\author{
Parcharidis I. ${ }^{1}$, Foumelis M. ${ }^{1}$ and Kourkouli P. ${ }^{1}$ \\ ${ }^{1}$ Harokopio University of Athens, Department of Geography, El. Venizelou 70, 176 71, Athens, Greece, \\ parchar@hua.gr,mfoum@hua.gr,pkourkouli@hua.gr
}

\begin{abstract}
Space borne differential synthetic aperture radar interferometry (DInSAR) has already proven its potential for mapping ground deformation phenomena, e.g. earthquakes, volcano dynamics, etc covering in continuity large areas.

The innovative Persistent Scatterers Interferometry (PSI) technique, which overcomes several limitations of conventional SAR differential interferometry especially for applications in landslide studies, is suitable for monitoring slope deformations with millimetric precision. With PSI technique we detect the deformation, for long periods, that occur in an area as average annual deformation ( $\mathrm{mm} / \mathrm{y})$ and is not spatially continuous but in terms of points (point targets).

The aim of this study is to present preliminary results on the monitoring of slope instability in Panachaiko Mountain and particularly of the slopes facing the city of Patras. For this purpose we processed and analysed 42 ERS 1 and ERS 2 SAR scenes acquired in the time span 1992 and 2001, by applying the Interferometric Point Target Analysis algorithm.

Point target reflectors with stable radar response over time were selected. In this case most of the point targets correspond to buildings of the local settlements or to rock outcrops. Additionally, millimetric target displacements along the line of sight direction were detected allowing measurements of slow terrain motion.
\end{abstract}

Key words: SAR Interferometry, Persistent Scatterers, IPTA algorithm, slope instability, Panachaico Mountain, Patras City.

\section{Introduction}

Numerous phenomena can induce displacements of the earth surface and thus cause disorders in structures and infrastructures particularly in urban areas. Landslides affect many areas of Greece and are characterized by low probability of evolution into a catastrophic event but can have very large direct and indirect impacts on man-made structures. Methodologies for the risk assessment and mitigation are therefore a major issue.

Conventional methods of ground deformation monitoring present many disadvantages such as high costs and time consuming. The space based Differential Interferometry SAR (DInSAR) techniques could present a valuable tool for detecting, monitoring, quantifying the deformation and with field- 


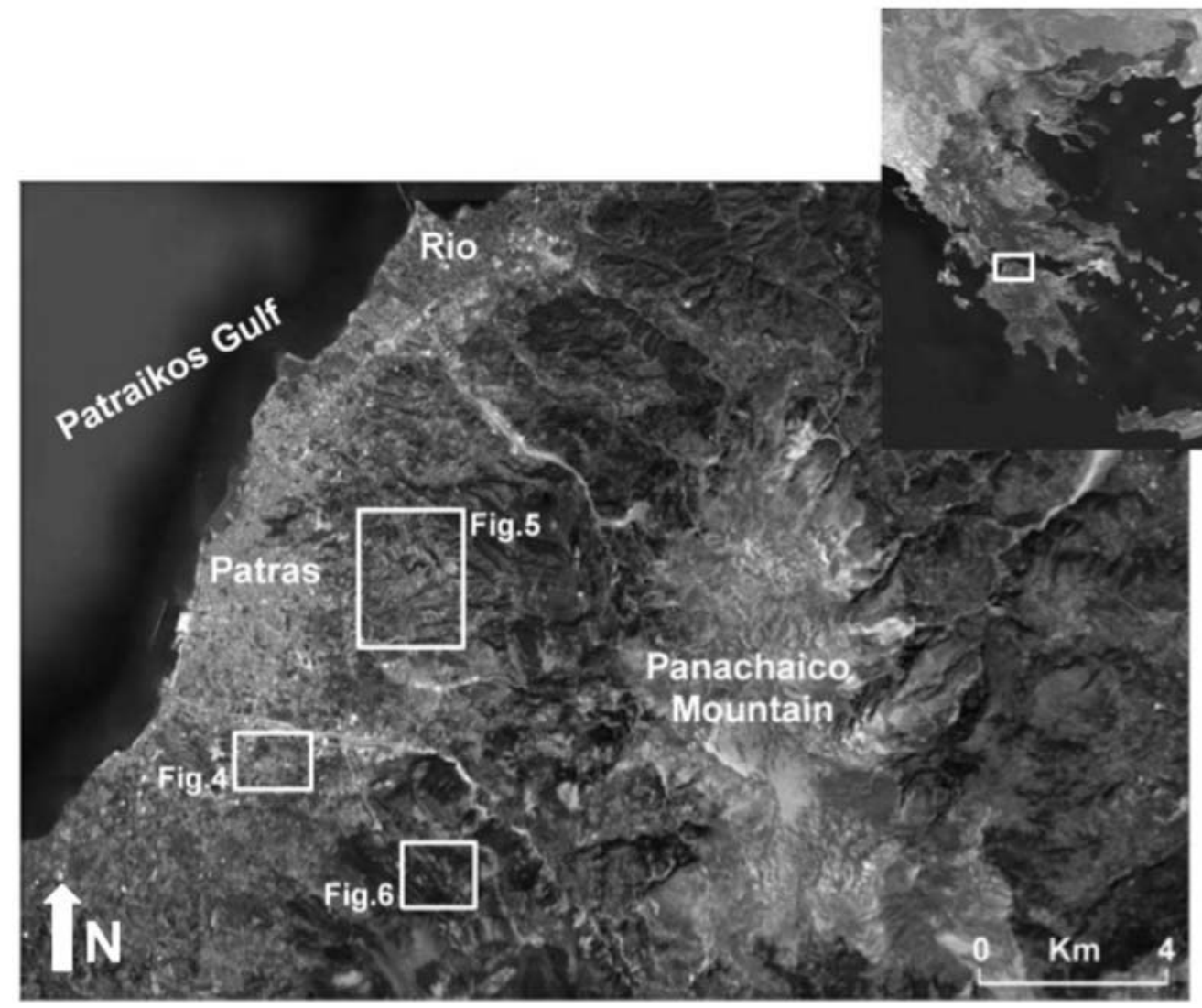

Fig. 1: Location map of the area (the frames are referred to the corresponding Figures).

work contribution can identify causes which may induce deformation.

DInSAR has already proven its potential for mapping ground deformation phenomena, e.g. earthquakes, volcano dynamics, etc and to cover in continuity large areas.

In recent years the innovative Persistent or Permanent Scatterers Interferometry (PSI) technique, which overcomes several limitations of repeat-pass interferometry, has been widely applied for monitoring of slope instability with millimetric precision (Delacourt 2003, Strozzi et al. 2005, Colesanti \& Wasowski 2006, Rott \& Nagler 2006, Corsini et al. 2006, Bovenga et al. 2006, Peyret et al. 2008, Meisina et al. 2008, Castaneda et al. 2009).

Significant difficulties are found when using this technique as an operational tool. These difficulties are related to the large variability of slope instabilities in terms of mechanisms of movement, failure geometries, size of unstable areas and deformation rates (Strozi et al. 2005). Some other limitations are connected to the acquisition parameters of the SAR platforms.

The aim of this study is to present preliminary results of an application of PS interferometry for detecting and monitoring of slope instability at regional and local scale, quantify the spatial distribution of surface deformation and analyze the time evolution of displacement, in Panachaiko Mountain 
and particularly of the slopes facing the city of Patras (Fig. 1). This site was chosen for the presence of a number of mass movements as it is mentioned from many authors (Sabatakakis et al. 2005, Koukis et al. 2007, Koukis et al 2009). For this purpose we processed and analysed a rich data set of ERS 1, ERS 2 SAR scenes, acquired in the time span 1992 and 2001, by applying the IPTA (Interferometric Point Target Analysis) method of the GAMMA s/w.

\section{Principles of Persistent Scatterers Interferometry (PSI)}

"Traditional" ground motion monitoring methods are based on field surveys. These methods include optical levelling, Global Position Systems, extensometers etc. During the last sixteen years the SAR Interferometric technique based on radar satellite data have become a useful tool for ground deformation detection and monitoring. Radar is an active sensor that alternatively sends out radio waves in form of pulses and records the echoes scattered back by objects (targets) hit by the waves along their travelling path. Each echo (backscattered signal) is a modified version of the transmitted pulse through the reflectivity function of the target(s) seen on the ground. Since the transmitted signal is a complex quantity, also the signal received by the radar is complex. It is composed by the magnitude, which is related to the power scattered back toward the sensor by the target, and the phase, which is expressed by the two-way path distance between the sensor and the target. Both amplitude of the radar signal and phase carry valuable information for the interferometric applications.

The magnitude and the phase of the complex interferograms are generally referred to as the degree of coherence (or simply coherence) and the interferometric (InSAR) phase respectively. The coherence measures the degree of correlation between two SAR images. The interferometric phase image has values between 0 and $2 \pi$ (or between $-\pi$ and $\pi$ depending on the representation used) and therefore appears as a series of fringes. The interferometric phase is a sensitive measure of the change in slant range.

Two consecutive fringes represent a phase difference of $2 \pi$. Areas of low coherence are characterized by noisy interferometric phase. Coherence is a measure of the phase noise or fringe visibility.

Since 1992, conventional 2-pass Differential InSAR (DinSAR) has been used by the scientific community to further study and understand specific ground deformation hazards. Normally this interferometric method is used to map ground deformation caused by a natural event like earthquake or landslide etc. What we need is the minimum of two SAR images one before and one after the event and also a Digital Elevation Model (DEM) of the area under study. The basic idea of differential interferometric processing is to separate the topography and displacement related phase terms allowing, in particular, the retrieval of a differential displacement map. This goal is achieved by subtracting the topography related phase using the DEM.

Repeat-pass Differential Interferometric techniques show limitations related to land-cover dependent temporal signal decorrelation and atmospheric propagation effects. Furthermore, the applicability of this interferometric technique depends also on the magnitude of the deformation. Recent developments (end of 90's) in differential interferometry have demonstrated some potential to overcome some of the above limitations of the conventional interferometry and also for more accurate and temporally dependent results. To maximize the precision with which displacement signals are detected, and to minimise effects like atmospheric the so-called Permanent or Persistent Scatterers Interferometry has been developed (Ferretti et al. 2001, Werner et al. 2003). This recent technique allows the calculation of fine motions of individual ground and structure points over wide areas (Fig. 2). By examining interferometric phase from stable, point-like targets, it is possible to moni- 


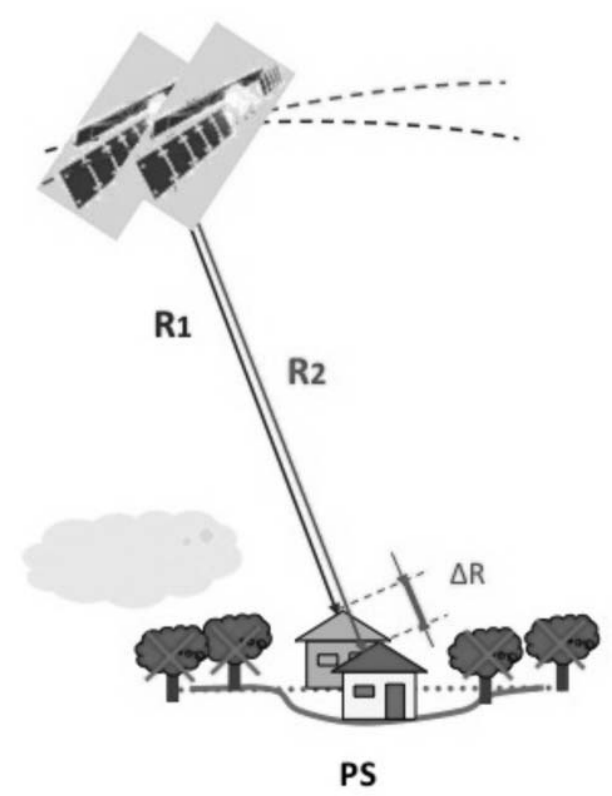

Fig. 2: The basic concept of the Persistent Scatterers Interferonetry methodology.

tor stability over areas that normally are characterized as "low coherence". Additionally, millimetric target displacements along the line of sight direction can be detected allowing measurement of slow terrain motion.

Interferometric Point Target Analysis (IPTA) is a specific method of PSI to exploit temporal and spatial characteristics of the interferometric signatures collected from point targets to map scatterer deformation history.

\section{Data used and processing}

As input data Single-Look Complex SAR images, from European remote sensing satellites ERS-1 and 2 operating at $\mathrm{C}$-band, have been used.

After an accurate searching at EOLI database ERS 1 \& 2 scenes covering the area of interest have been ordered. A total number of 42 ERS archive scenes, track: 279 and frame: 2835, covering the period 1992-2001 (Table 1) were acquired. The acquisitions have descending orbit that means with line of sight (LOS) approximately ESE-WNW.

Persistent Scatterers Interferometry (PSI) is a technique used to calculate fine motions of individual ground and structures points over wide areas. These reflectors should remain stable (interferometric phase stability over time). Interferometric Point Target Analysis (IPTA) is a specific method of PSI, developed by GAMMA Remote Sensing (Switzerland) to exploit temporal and spatial characteristics of interferometric signatures collected from point targets to map scatterer deformation history (Werner et al., 2003).

Interferometric processing for the selected study area was performed using 42 ERS- 1 and 2 SAR scenes acquired between 1992 and 2001 along descending track 279. Initial estimates of the interferometric baselines were calculated from available precise orbit state vectors from Delft Institute 
Table 1.

\begin{tabular}{|c|c|c|c|c|c|}
\hline Count & Satellite & Slave (date) & Orbits & Bp (meters) & dT (days) \\
\hline 1 & ERS 1 & $11 / 12 / 1992$ & 6937 & 73.913 & -933 \\
\hline 2 & ERS 1 & $06 / 10 / 1993$ & 9943 & -477.395 & -723 \\
\hline 3 & ERS 1 & $08 / 19 / 1993$ & 10945 & -323.744 & -653 \\
\hline 4 & ERS 1 & $10 / 28 / 1993$ & 11947 & 569.7341 & -583 \\
\hline 5 & ERS 1 & $03 / 25 / 1995$ & 19305 & -1169.985 & -70 \\
\hline 6 & ERS 1 & $04 / 29 / 1995$ & 19806 & -518.4969 & -35 \\
\hline 7 & ERS 1 & $06 / 03 / 1995$ & 20307 & 0 & 0 \\
\hline 8 & ERS 1 & $07 / 08 / 1995$ & 20808 & -583.3577 & 35 \\
\hline 9 & ERS 2 & $08 / 13 / 1995$ & 1636 & 82.8884 & 71 \\
\hline 10 & ERS 2 & $09 / 17 / 1995$ & 2137 & -360.0171 & 106 \\
\hline 11 & ERS 1 & $10 / 21 / 1995$ & 22311 & 761.2519 & 140 \\
\hline 12 & ERS 2 & $12 / 31 / 1995$ & 3640 & 186.241 & 211 \\
\hline 13 & ERS 2 & $05 / 19 / 1996$ & 5644 & 71.012 & 351 \\
\hline 14 & ERS 2 & $06 / 23 / 1996$ & 6145 & -83.809 & 386 \\
\hline 15 & ERS 2 & $09 / 01 / 1996$ & 7147 & -514.627 & 456 \\
\hline 16 & ERS 2 & $10 / 06 / 1996$ & 7648 & -392.684 & 491 \\
\hline 17 & ERS 2 & 11/10/1996 & 8149 & 1064.863 & 526 \\
\hline 18 & ERS 2 & $12 / 15 / 1996$ & 8650 & -309.172 & 561 \\
\hline 19 & ERS 2 & $01 / 19 / 1997$ & 9151 & -28.695 & 596 \\
\hline 20 & ERS 2 & $02 / 23 / 1997$ & 9652 & -182.299 & 631 \\
\hline 21 & ERS 2 & $05 / 04 / 1997$ & 10654 & -360.3074 & 701 \\
\hline 22 & ERS 2 & $06 / 08 / 1997$ & 11155 & -166.9323 & 736 \\
\hline 23 & ERS 2 & $07 / 13 / 1997$ & 11656 & -124.871 & 771 \\
\hline 24 & ERS 2 & $08 / 17 / 1997$ & 12157 & 111.4587 & 806 \\
\hline 25 & ERS 2 & $09 / 21 / 1997$ & 12658 & -263.2312 & 841 \\
\hline 26 & ERS 2 & 11/30/1997 & 13660 & 177.4578 & 911 \\
\hline 27 & ERS 2 & $01 / 04 / 1998$ & 14161 & 116.4249 & 946 \\
\hline 28 & ERS 2 & $04 / 19 / 1998$ & 15664 & 193.0535 & 1051 \\
\hline 29 & ERS 2 & $05 / 24 / 1998$ & 16165 & -160.6964 & 1086 \\
\hline 30 & ERS 2 & $06 / 28 / 1998$ & 16666 & -834.8781 & 1121 \\
\hline 31 & ERS 2 & $08 / 02 / 1998$ & 17167 & 56.7021 & 1156 \\
\hline 32 & ERS 2 & 09/06/1998 & 17668 & 47.0451 & 1191 \\
\hline 33 & ERS 2 & $02 / 28 / 1999$ & 20173 & 302.9872 & 1366 \\
\hline 34 & ERS 2 & $06 / 13 / 1999$ & 21676 & -559.7601 & 106 \\
\hline 35 & ERS 2 & $07 / 18 / 1999$ & 22177 & 455.9664 & 1506 \\
\hline 36 & ERS 2 & $08 / 22 / 1999$ & 22678 & 1012.1175 & 1541 \\
\hline 37 & ERS 2 & $09 / 26 / 1999$ & 23179 & 448.5963 & 1576 \\
\hline 38 & ERS 2 & 10/31/1999 & 23680 & 357.309 & 1611 \\
\hline 39 & ERS 2 & $12 / 05 / 1999$ & 24181 & -121.9885 & 1646 \\
\hline 40 & ERS 2 & $01 / 09 / 2000$ & 24682 & -140.144 & 1681 \\
\hline 41 & ERS 2 & $04 / 23 / 2000$ & 26185 & 953.687 & 1786 \\
\hline 42 & ERS 2 & $05 / 28 / 2000$ & 26686 & 806.600 & 1821 \\
\hline
\end{tabular}


(NL) for Earth-Oriented Space Research (DEOS) (Scharoo and Visser, 1998). The topographic phase was simulated based on SRTM v2 DEM of approximate spatial resolution of $90 \mathrm{~m}$.

Starting from a stack of co-registered SLC images, the selection of the reference scene was based primarily on the baseline minimization criteria. In addition, the selection of a reference scene acquired near the temporal average of the available SAR acquisitions is also of interest. For the specific project the ERS scene acquired on 3 June-1995 with orbit number 20307 was selected as reference scene.

The first step of the analysis involves the identification of candidate point targets for which the timeseries analysis will be performed. In this case two different approaches were applied. The first approach is based on the spectral properties of each individual SLC image. This is done by identifying point targets of low spectral phase diversity. The second approach involves the identification of candidate point targets based on low intensity variability, since by definition point targets do not show speckle behaviour as simple coherent scatterer dominates the echo. Finally, point targets determined previously were combined into a single preliminary point list containing a total number of 78,647 records. At this stage of the analysis the distribution of point targets seems not to be restricted over flat areas, but also show significant presence over mountainous regions.

The analysis of the differential interferometric phases in the temporal direction is an important element of an interferometric point target analysis. Point data stack of differential interferograms was generated and analyzed by means of phase regression analysis in the temporal domain using two dimensional bi-linear regression model.

Two dimensional regression analysis is done with the dimensions corresponding to the perpendicular baseline of the interferometric pairs and to the time difference between the two SLC of the interferometric pairs according to:

$$
\mathrm{a} 0+\mathrm{a} 1 * \text { bperp }[\mathrm{i}]+\mathrm{a} 2 * \text { delta } \mathrm{t}[\mathrm{i}]
$$

a0: phase offset, a1: slope in baseline dimension (can be converted into point height correction), a2: slope in time dimension (can be converted into linear deformation rate), bperp: perpendicular baseline component of interferograms, and delta_t: time interval of interferograms.

The model examines linear dependence of the topographic phase on the perpendicular baseline component as well as linear phase dependence with time, solving respectively for both height correction and constant deformation rate of the point target relative to the reference. The regression analysis of the entire stack of observations was first conducted using multiple patches, within each patch one reference is determined, and then using the selected single reference point as a global reference. This procedure was followed in order to minimize the effect of distance between the two pairs phase components, as the atmospheric distortion, baseline error (residual orbital phase trends) and higher relative deformation rates result in higher deviations of the individual points from the regression plain.

The quality of the preliminary candidate points were then carefully evaluated based on the estimated standard deviation of the differential interferometric phase from the 2-D regression model. Points with a phase standard deviation larger than the indicated threshold (in this case 1.0) were rejected reducing significantly the number of scatterers to 3353 over the study area. The majority of the rejected points were located over mountainous areas non build-up zones.

The general phase model for IPTA that used is the same as the conventional interferometry. The unwrapped interferometric phase $\Phi_{\text {unw }}$ is expressed as the sum of topographic phase $\Phi_{\text {topo }}$, deformation phase $\Phi_{\text {def }}$, path delay (atmospheric phase) $\Phi$ atm and the phase noise $\Phi$ noise. 


$$
\Phi \text { unw }=\Phi \text { topo }+\Phi \text { def }+\Phi \text { atm }+\Phi \text { noise (Werner et al., 2003) }
$$

Phase terms related to the atmosphere, non-linear deformation, baseline errors and noise could be discriminated within the residual phases based on their differing spatial and temporal dependencies (Werner et al., 2003).

Unwrapped phases calculated from the regression analysis described above and the corresponding topographic phases were then used in a least-squares approach for baseline refinement. The analysis was limited over areas exhibiting no deformation as dictated by the linear deformation estimates. Introducing the refined baselines and taking into consideration the early estimated height corrections and linear deformation rates, the interferometric phase model was updated in a second iteration.

Additional processing includes temporal and spatial filtering of newly estimated residual phases to compensate for atmosphere and noise. Atmospheric screen was attributed to large scale non-linear residuals and subtracted from the model by applying low-pass spatial filtering on the residual phases. Phase noise was treated by spatially filtering of phases around the reference, assuming stability of the area considered.

Further iteration applying the additional corrections results in the final regression model. Results consist of point heights, linear deformation rates, atmospheric phase, refined baselines, quality information (temporal coherence) and non-linear deformation histories for each point. It is important to mention that the final deformation model, as a consequence of the assumptions made during the estimation.

\section{Analysis-Interpretation}

After transformation of the interferometric results from range-Doppler coordinates into map geometry (geographic coordinates), point targets were imported in a GIS environment and plotted on a panchromatic Landsat-7 ETM+ image and in Google Earth environment for point targets identification (Fig. 3). The majority of the targets correspond to the buildings forming villages.

In this location slopes face west and north-west making the descending scenes suitable for the interferometric application. Phenomena like layover and foreshortening are not recognised in the average multi-look reflectivity image.

The displacement rates, along the line of sight (LOS), vary from -4.6 to $7 \mathrm{~mm} /$ year for the entire area of processing. In total 1073 persistent scatterers were identified. Negative values indicate displacement away from the radar sensor, towards down slope in this case. Examining the scatterers and their rates of displacement on a more detail scale we noticed groups of targets presenting negative values. A typical case is the Demenika village where the values of the targets vary between -3.1 and $0.7 \mathrm{~mm} /$ year (Fig. 4). Additionally, targets with negative values are observed over the tunnel of the new suburban national road with rates between -4.0 and $0.2 \mathrm{~mm} /$ year (Fig. 5).

A distinct case in our results concerns a group of point targets over a slope, one kilometre towards NE of Moni Omplou. These targets have negative values and correspond not to human structures but to rocks outcrops (Fig. 6).

Finally the historic deformation diagrams for specific point targets from the above sites were created (Fig. 7) showing the tendency of the displacement during the time span (1992-2001).

\section{Results-Discussion}

In this study a dataset of Envisat scenes were processed using the IPTA algorithm in order to create 


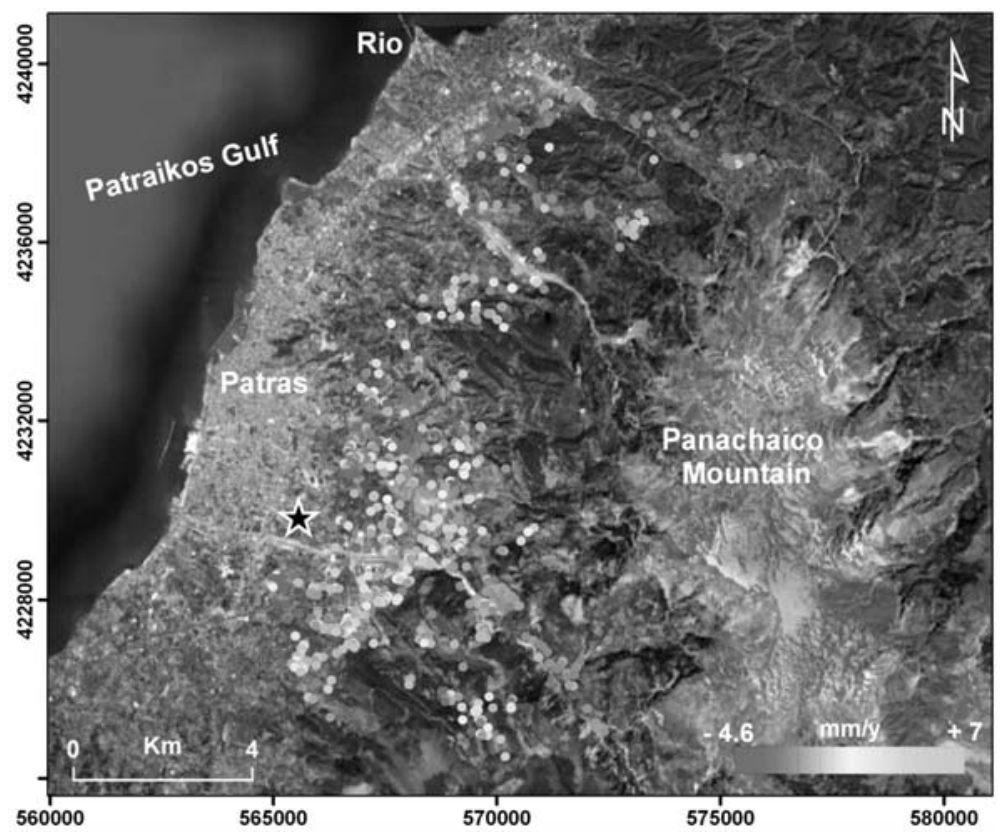

Fig. 3: Linear deformation rates for point targets estimated over the study area and plotted on a QuickBird satellite image

a persistent scatterers deformation map in order to detect soil instability over the Panachaiko slopes facing Patras city. Produced results show areas with negative values that means a displacement away from the satellite. These areas could correspond with areas of ground instability. For specific targets the historical deformation diagrams were created. Interferometric results should be accompanied by detailed field work verify the interferometric results. Based on the observation that even over villages the point targets are few a new processing with the selected reference point much close at the areas of interest probably will increase the number of targets and thus the points of measurements. Generally speaking, the persistent scatterers interferometry approach offers an alternative in respect to the "conventional" or repeat-pass interferometry. With this technique the corresponding stable point targets can be identified and analyzed their displacement in time. The main limitations (Colesanti and Wasowski 2006, Rott and Nagler 2006) of PSI to identify landslides are related to:

- One dimensional deformation data provision along the line of sight.

- A limited range of detectable displacements (up to $10 \mathrm{~cm} / \mathrm{yr}$ ) focusing only on very slow slope deformation.

- Limited rock outcrops and buildings in the area so the detectable persistent scatterers are very few. 


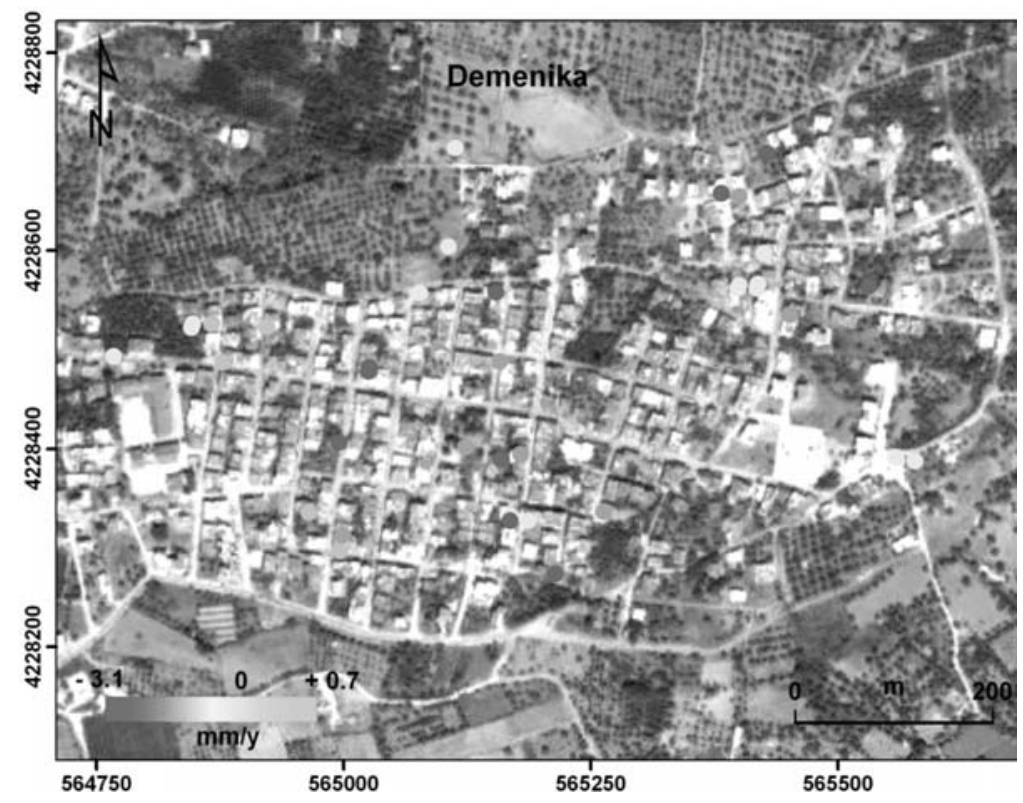

Fig. 4: Linear deformation rates for point targets estimated over Demeniko village

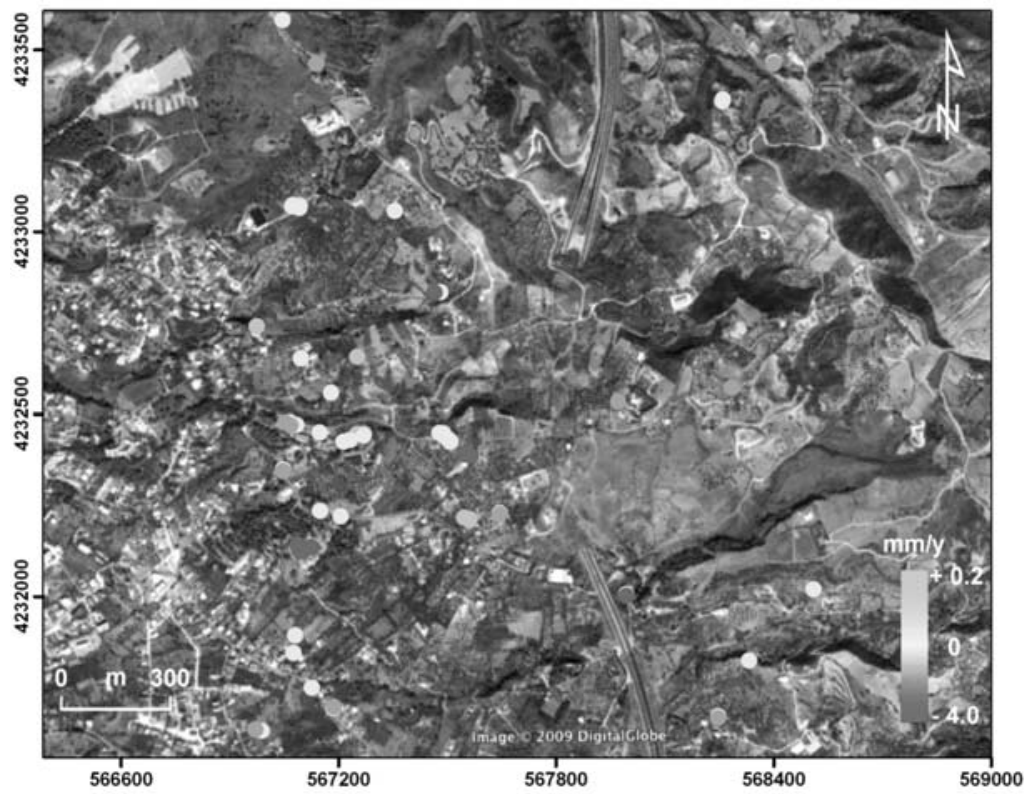

Fig. 5: Linear deformation rates for point targets estimated over the tunnelling area 


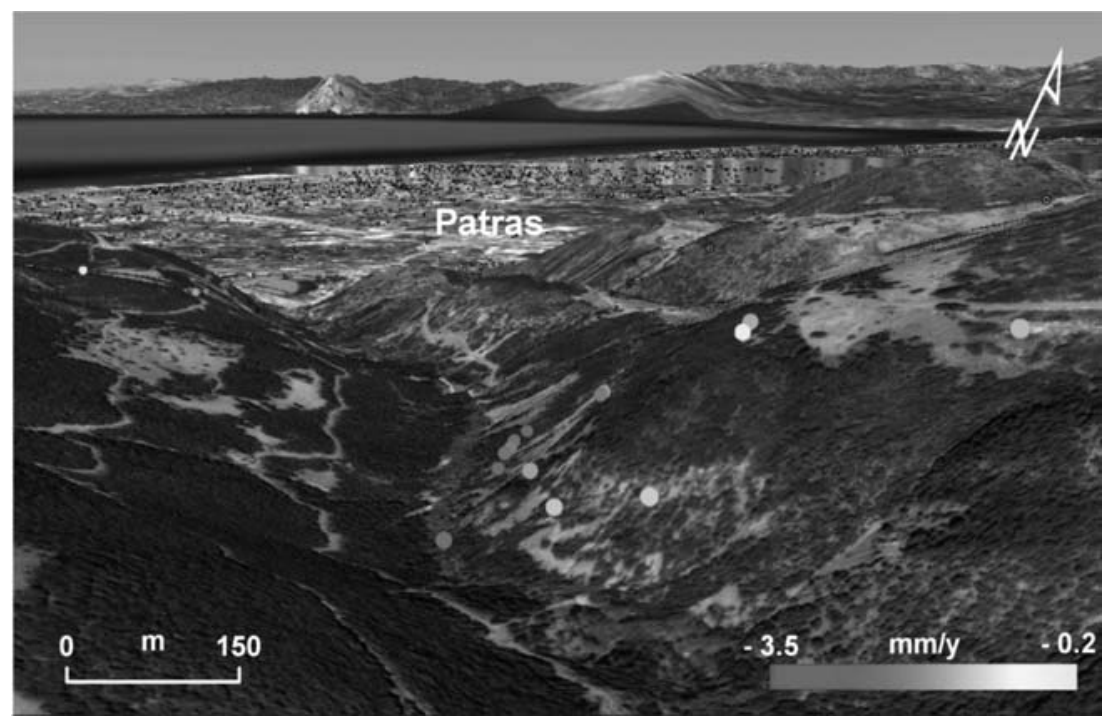

Fig. 6: Linear deformation rates for point targets estimated over the Moni Omplou slope
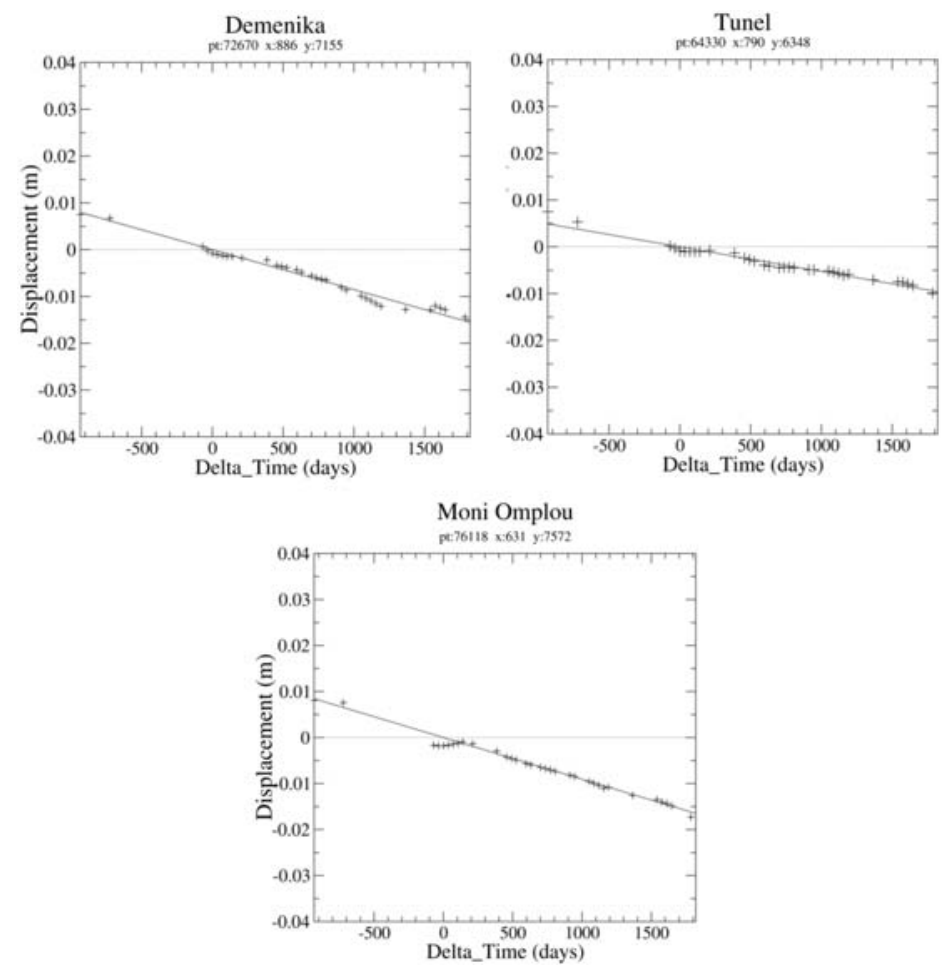

Fig. 7: Typical displacement histories (1992-2001) for specific point targets in the three areas showing a displacement away from the sensor. Values lie within about $0.2 \mathrm{~cm}$ of the linear rate with a standard deviation significantly below $1 \mathrm{rad}$. 


\section{References}

Bovenga F., Nutricato R., Refice A. and Wasowski J., 2006. Application of multi-temporal differential interferometry to slope instability detection in urban/peri-urban areas. Engineering Geology 88, 218239.

Castaneda C., Gutierrez F., Manunta M. and Galve J., 2009. DInSAR measurements of ground deformation by sinkholes, mining subsidence and landslides, Ebro River, Spain. Earth Surface Processes and Landforms 34, 1562-1574.

Colesanti C. and Wasowski J., 2006. Investigating landslides with space-borne Synthetic Aperture Radar (SAR) interferometry. Engineering Geology 88, 173-199.

Corsini A., Farina P., Antonello G., Barbieri M., Casagli N., Coren F., Guerri L., Ronchetti F., Sterzai P., Tarchi D., 2006. Space-borne and ground-based SAR interferometry as tools for landslide hazard management in civil protection. International Journal of Remote Sensing 27(12), 2351-2369.

Delacourt C., Allemand P., Squarzoni C., Picard F., Raucoules D., Carnec C., 2003. Potential and limitation of ERS-Differential SAR Interferometry for landslide studies in the French Alps and Pyrenees. In proceedings of FRINGE 2003.

Ferretti, A.; Prati, C.; Rocca, F., 2001. Permanent scatterers in SAR interferometry. IEEE T. Geosci. Remote, 39, 8-20.

Koukis G., Sabatakakis N., Lainas S., 2007. Soil suitability estimation for housing purposes in landslideprone areas. The case of Karya Village, Patras, W, Greece. Bulletin of the Geological Society of Greece, vol. XXXVII,

Koukis G., Sabatakakis N., Ferentinou M., Lainas S., Alexiadou X., Panagopoulos A., 2009. Landslaide phenomena related to major fault tectonics: rift zone of Corinth Gulf, Greece. Bull. Eng. Geol. Environ. DOI 10.1007/s10064-008-0184-8.

Meisina C., Zucca F., Notti D. Colombo A., Cucchi A., Savio G., Giannico C. and Bianchi M., 2008. Sensors 8, 7469-7492.

Peyret M., Djamour Y., Rizza M., Ritz J.-F., Hurtrez J.-E., Goudarzi M, Nankali H., Chery J., Le Dortz K., Uri F., 2008. Monitoring of the large slow Kahrod landslide in Alborz mountain range (Iran) by GPS and SAR interferometry. Engiheering Geology 100, 131-141.

Rott H. and Nagler T., 2006. The contribution of radar interferometry to the assessment of landslide hazards. Advances in Space Research, 37, 710-719.

Sabatakakis N., Koukis G., Mourtas D., 2005. Composite landslides induced by heavy rainfalls in suburban areas: city of Patras and surrounding area, western Greece. Landslides 2, 202-211.

Scharoo R. and Visser P.N.A.M., 1998. Precise orbit determination and gravity field improvement for the ERS satellites. Journal Geophysical Research, vol. 103, 8113-8127.

Strozzi T., Farina P., Corsini A., Ambrosi C., Thüring M., Zilger J., Wiesmann A., Wegmüller U., Werner C., 2005. Survey and monitoring of landslide displacements by means of L-band satellite SAR interferometry. Landslides 2 (3), 193-201.

Werner, C.; Wegmüller, U.; Strozzi, T.; Wiesmann, A. (2003). Interferometric point target anaysis for deformation mapping. In Proceedings of the IEEE International Geoscience and Remote Sensing Symposium, Toulouse, France, July 2003, 7, 4362-4364. 
